\title{
Influence of dissolved organic matter on the bioavailability of hydrophobic organic pollutants in sediments investigated by bioassays
}

\author{
Klaus Wruss*, Dragana Todorovic and Andrea P Loibner
}

Address: Department of Environmental Biotechnology, IFA Tulln, Austria

Email: Klaus Wruss* - klaus@taonet.at

* Corresponding author

\author{
from 13th Scientific Symposium of the Austrian Pharmacological Society (APHAR). Joint Meeting with the Austrian Society of Toxicology (ASTOX) and the \\ Hungarian Society for Experimental and Clinical Pharmacology (MFT) \\ Vienna, Austria. 22-24 November 2007 \\ Published: 14 November 2007 \\ BMC Pharmacology 2007, 7(Suppl 2):A66 doi:10.1 I86/I47|-2210-7-S2-A66
}

This abstract is available from: http://www.biomedcentral.com/I47I-22/0/7/S2/A66

(C) 2007 Wruss et al; licensee BioMed Central Ltd.

Only little attention has been paid to hetero polycyclic aromatic hydrocarbons (N-, S- or O-substituted PAHs), a group of substances which is found together with PAHs. Hetero PAHs typically show a higher water solubility and a higher bioavailability than the structurally corresponding PAHs. The focus was to study the toxicity of fluorene and the similar hetero PAHs as carbazole, dibenzothiophene and dibenzofuran. Bioassays were carried out with Heterocypris incongruens (Ostracod Toxkit F) and Vibrio fischeri (Lumistox). H. incongruens show the highest sensitivity to carbazole, $V$. fischeri are most sensitive to dibenzofuran from the studied substances. In the presence of natural sediment toxicity was dramatically reduced. This effect can be deduced to the presence of organic matter (e.g. humic acids) in solid and dissolved form. A aqueous mix of all tested PAHs showed different toxicity results compared to the tested single substances. An explanation for this result is presented. No additive toxicity effects could be observed. 